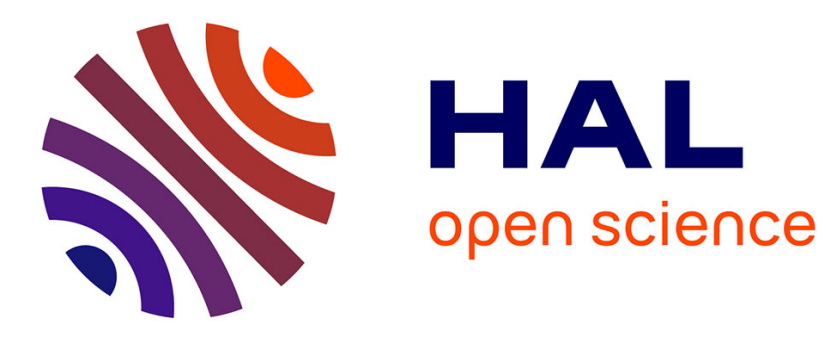

\title{
Transport of organic solvents through natural rubber/nitrile rubber/organically modified montmorillonite nanocomposites
}

Hanna Maria, Nathalie Lyczko, Ange Nzihou, Cherian Mathew, Soney C.

George, Kuruvilla Joseph, Sabu Thomas

\section{To cite this version:}

Hanna Maria, Nathalie Lyczko, Ange Nzihou, Cherian Mathew, Soney C. George, et al.. Transport of organic solvents through natural rubber/nitrile rubber/organically modified montmorillonite nanocomposites. Journal of Materials Science, 2013, 48 (15), p. 5373 - 5386. 10.1007/s10853-0137332-7 . hal-01630229

\section{HAL Id: hal-01630229 \\ https://imt-mines-albi.hal.science/hal-01630229}

Submitted on 6 Nov 2019

HAL is a multi-disciplinary open access archive for the deposit and dissemination of scientific research documents, whether they are published or not. The documents may come from teaching and research institutions in France or abroad, or from public or private research centers.
L'archive ouverte pluridisciplinaire HAL, est destinée au dépôt et à la diffusion de documents scientifiques de niveau recherche, publiés ou non, émanant des établissements d'enseignement et de recherche français ou étrangers, des laboratoires publics ou privés. 


\title{
Transport of organic solvents through natural rubber/nitrile rubber/organically modified montmorillonite nanocomposites
}

\author{
Hanna J. Maria • Nathalie Lyczko • \\ Ange Nzihou - Cherian Mathew - Soney C. George • \\ Kuruvilla Joseph $\cdot$ Sabu Thomas
}

\begin{abstract}
The article describes the transport phenomenon of some commonly used laboratory organic solvents which differ in their solubility parameter value through polymer blend nanocomposites membrane prepared by melt mixing. The three solvents that were used are hexane, toluene and xylene which differed widely in their solubility parameter values. The motivation for the study was to know the effect of solubility parameter on the diffusion transport properties of NR/NBR (natural rubber/nitrile rubber) blends. The solvent uptake, diffusion, sorption and permeation constants were investigated and were found to decrease with organically modified montmorillonite (OMt) content at lower loading. The mode of transport through NR/NBR nanocomposites was found to be anomalous. The difference in solubility parameter value greatly influenced the transport properties. The dependence of various properties on OMt content was supported by morphological analysis data. The
\end{abstract}

H. J. Maria · S. Thomas (凶)

School of Chemical Sciences, Mahatma Gandhi University, Priyadarsini Hills P.O., Kottayam 686560, Kerala, India e-mail: sabupolymer@yahoo.com;

sabuchathukulam@yahoo.co.uk

H. J. Maria $\cdot$ C. Mathew

Department of Chemistry, S. B. College, Changanacherry, Kottayam, Kerala, India

N. Lyczko · A. Nzihou

Université de Toulouse, Mines Albi, CNRS, Centre

RAPSODEE, Campus Jarlard, 81013 Albi Cedex 09, France

S. C. George

Amal Jyothi College of Engineering, Kottayam, Kerala, India

K. Joseph

Department of Space, Indian Institute of Space Science and

Technology, Thiruvanathapuram, Kerala, India effect of blend ratio, solvent size and OMt loading on the diffusion of aromatic and aliphatic solvents through NR/ NBR blend systems were investigated. The swelling coefficient values also decreased upon the addition of fillers indicating the presence of hindered path for solvents to diffuse into the polymer matrix. The better reinforcement at lower filler loading was confirmed from the cross-link density values and mechanical properties. The transport data obtained were applied to mathematical models for predicting the diffusion behaviour through nanocomposite membranes and to elucidate the physical mechanism of transport.

\section{Introduction}

Polymer composite science and technology is a very large and rapidly growing area. Although the polymer composites may not corrode via the same mechanisms as metals,

S. Thomas

Centre for Nanoscience and Nanotechnology, Mahatma Gandhi

University, Priyadarshini Hills, Kottayam, Kerala, India

S. Thomas

Faculty of Applied Sciences, Universiti Teknologi MARA, 40450 Shah Alam Selongor, Malaysia

S. Thomas

Center of Excellence for Polymer Materials and Technologies, Tehnoloski park 24, 1000 Ljubljana, Slovenia 
when exposed to moisture, hazardous solvents, UV radiation etc, polymer composites have a tendency to undergo plasticization and degradation. This results in deterioration of mechanical properties and reduction in the life of composite structures. Polymer nanocomposites, made by dispersing nanosized particles, can solve this problem to a great extent by reducing the diffusivity of moisture and other molecules in polymer composites. One of the unique properties of nanocomposites, especially layered silicate layered silicate filled nanocomposites are their resistance to penetration of solvents and gases which make it applicable in many fields. Solvent resistant membranes have a strong potential for a variety of applications. This can be used as a technique to elucidate the relation between processes of mass transport, solubility, transport in polymers, their molecular properties, nature of penetrates, polymer morphology of the interface, deformation and morphology. The transport of small molecules through polymer membrane occurs due to random molecular motion of individual molecules [1] Therefore, the transport behaviour of various organic solvents and gases through polymers is of great technological importance and it plays a vital role in a variety of barrier applications [2].

The effect of fillers on the transport characteristics of polymers has been of immense interest to scientists. The effect of fillers on the diffusion and sorption processes has been reported [3, 4]. The sorption of chloroform by an epoxy resin was lowered by about $70 \%$, when $5 \%$ filler was incorporated [5]. The study of diffusion, sorption and permeation in blend structures provide valuable means for additional characterization of polymer blends [6]. Blend composition, miscibility and phase morphology are the main determining factors of transport properties through polymer membranes. For immiscible blends, the nature of the two polymers and the interface influence the transport properties. Solvent resistant properties of nano-structured layered silicates filled blend of NR and carboxylated styrene butadiene rubber (XSBR) were investigated by Ranimol et al. [7, 8] The study of barrier properties through poly (ethylene-co-vinyl acetate)/clay nanocomposites with

Table 1 Properties of the materials used

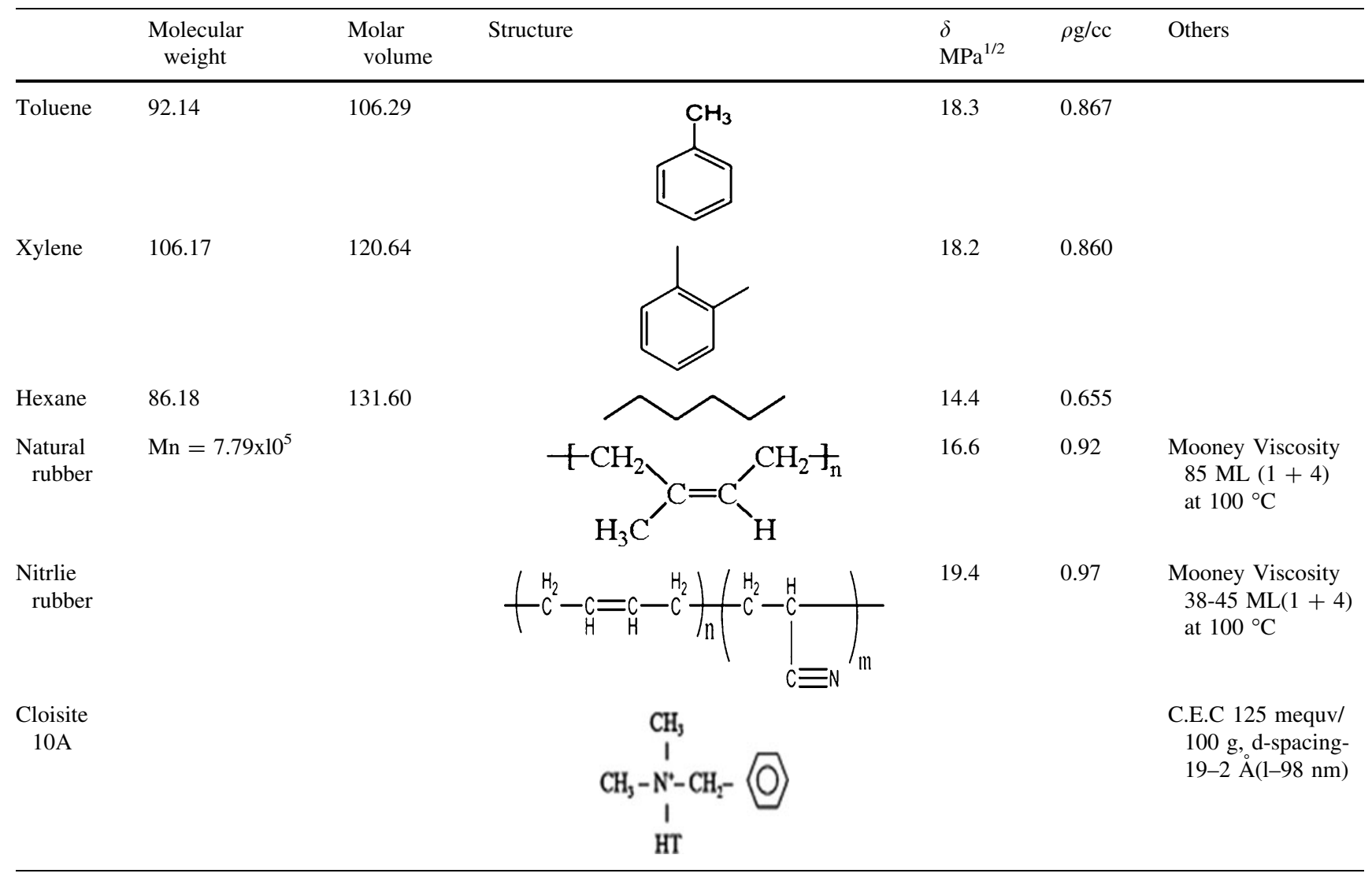


different organic modification revealed that the incorporation of $\mathrm{OMt}$ in the polymer, increased the barrier properties [9, 10]. The swelling properties of filled natural rubber/linear low-density polyethylene blends was investigated by Ahmad et al. [11] and was found that the swelling index decreased with increase in filler loading.

The present study was motivated by a desire to know how the nanoparticles in an immiscible blend system affect its transport properties. No reports are there up to our knowledge regarding the transport properties in NR/NBR elastomer blend system, where OMt act as a reinforcing and compatibilizing agent. Organic solvents are harmful to humans and are identified as carcinogens, especially when it comes into contact with the skin. Thus, the transport studies in NR/NBR blend nanocomposites are of much interest from many points of view, especially the potential use of this blend in glove manufacturing industry. The presence of fillers in this NR/NBR blend system can further enhance the properties of gloves by improving its transport and mechanical properties. The potential application of this blend nanocomposites in glove manufacturing industry will be a matter of future publication. The discussion in this paper involves the work undertaken to investigate the transport characteristics of NR/NBR blend nanocomposites, in commonly used laboratory organic solvents which differ in their solubility parameter values. The effect of OMt on the blend composition, and clay loading, were also taken into account while investigating the transport properties of these blend nanocomposites.

\section{Experimental part}

\section{Materials}

Natural rubber (NR) ISNR 5, supplied by The Rubber Board, Kottayam, India had the number average molecular weight of $3 \times 10^{5} \mathrm{~g} / \mathrm{mol}$ and a weight average molecular weight of, Mw $7.8 \times 10^{5} \mathrm{~g} / \mathrm{mol}$, [12] and Mooney Viscosity $85 \mathrm{ML}$ $(1+4)$ at $100{ }^{\circ} \mathrm{C}$. Nitrile rubber NBR (Chemigum $\left.{ }^{\circledR} \mathrm{N} 344\right)$ with $33 \%$ acrylonitrile content with Mooney viscosity of 38-45 ML $(1+4)$ at $100{ }^{\circ} \mathrm{C}$ and specific gravity of about 0.98 was supplied by Eliokem industries Ltd. Mumbai. The organically modified montmorillonite used in this present study was Cloisite 10A (Montmorillonite with organic modification dimethyl, benzyl, one alkyl tail i.e. hydrogenated Tallow (HT)(65 m \%. C18, $30 \mathrm{~m} \%$. C16, $5 \mathrm{~m} \%$. $\mathrm{C} 14)$ modification provided by Southern Clay Products. The cation exchange capacity (CEC) was equal to $125 \mathrm{meq} /$ $100 \mathrm{~g}$ and an average dry particle size in the range $2-13 \mu \mathrm{m}$. The solvents used were xylene, toluene and hexane. The specifications regarding the materials used are given in (Table 1) [13, 14].

\section{Preparation of the blend nanocomposites}

The nanocomposites were compounded according to the formulation given in (Table 2) with the aid of a laboratorysized two roll mixing mill $(150,300 \mathrm{~mm})$. The NR/NBR blends were compounded according to ASTM D 3182 (American Society for Testing and Materials). For all the mixes the nip gap, roll speed ratio, and the number of passes were kept constant. The temperature range for mixing was $70-90{ }^{\circ} \mathrm{C}$. After mixing, the rubber compositions were moulded in an electrically heated hydraulic press to the optimum cure using moulding conditions. An oscillating disc rheometer (MFR) was used to analyze the cure characteristics and the analysis was done at a temperature of $150^{\circ} \mathrm{C}$ (Table 3). The composites were cured at their respective cure times in a hydraulic press under a pressure of about 120 bar at $150{ }^{\circ} \mathrm{C}$. Round shaped samples of $2 \mathrm{~mm}$ of thickness were used for the diffusion study. All the blend compositions from now on will be represented in the order of NR/NBR.

\section{Procedure for sorption experiment}

The pat and weigh technique was used for the diffusion studies. The whole experiment was done at room temperature. Uniform sized round cut samples of the nanocomposites samples were weighed on an electronic balance. The cured samples cut into round shapes were put into sample bottles with covers. Nearly $20 \mathrm{ml}$ of solvent was poured into each of the sample bottles. At the expiration of the specified time, the samples were removed from the sample bottles, wiped free of adhering solvent and weighed using an electronic balance. The weighing was continued till equilibrium swelling was attained. Each weighing was completed at the earliest, so as to decrease the error due to solvent evaporation from the sample surface. All the experiment were done at a temperature of $30^{\circ} \mathrm{C}$ and was repeated for each nanocomposites studied.

\section{Morphological analysis}

The morphology of the cryofractured composites was analyzed by scanning electron microscopy FEI/Philips XL30 FEG ESEM, with electron backscatter diffraction analysis and energy-dispersive X-ray capability. To assess the quality of filler dispersion and morphological details, the blend nanocomposite were investigated by means of TEM (JEM-2100HRTEM). The micrographs were obtained in point to point resolution of $0.194 \mathrm{~nm}$, operating at an accelerating voltage of $200 \mathrm{kV}$. The cryocut specimens prepared using an ultra-microtome (Leica, Ultracut UCT) were placed on a 300 mesh $\mathrm{Cu}$ grids ( $35 \mathrm{~mm}$ diameter) and were analysed. XRD of the clay nanocomposites were done 


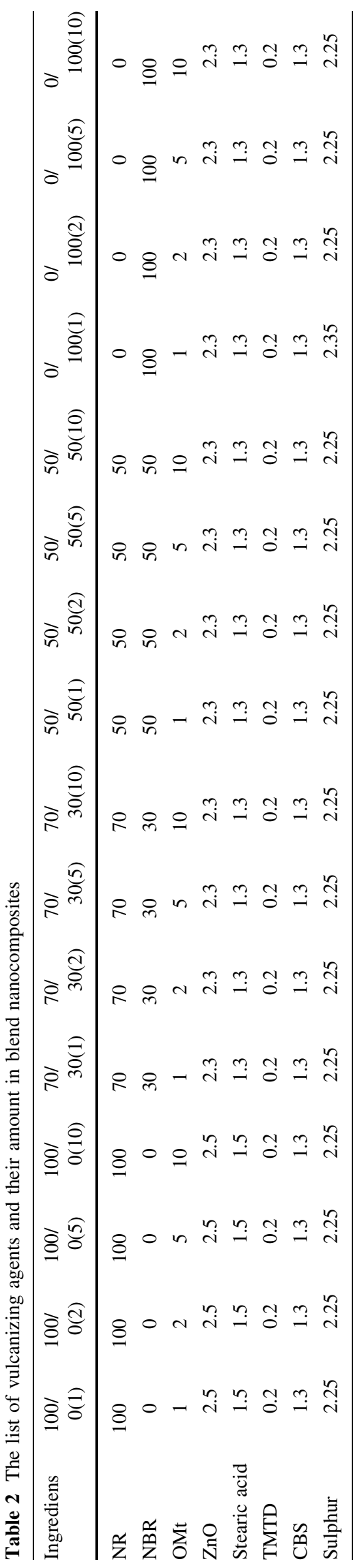

Table 3 Cure time data of the NR/NBR blend nanocomposites

\begin{tabular}{lll}
\hline Cure data of NR/NBR blend nanocomposites & \\
\hline Sample & Ts2 & T90 \\
\hline $100 / 0(0)$ & 1.75 & 5.03 \\
$100 / 0(2)$ & 0.82 & 2.05 \\
$100 / 0(5)$ & 0.63 & 2 \\
$100 / 0(10)$ & & 1.7 \\
$0 / 100(0)$ & 2.7 & 6.4 \\
$0 / 100(2)$ & & 2.27 \\
$0 / 100(5)$ & 1.64 & 5.04 \\
$0 / 100(10)$ & & 2.04 \\
$70 / 30(0)$ & 1.61 & 3.39 \\
$70 / 30(2)$ & & 1.96 \\
$70 / 30(5)$ & 1.63 & 3.39 \\
$70 / 30(10)$ & & 1.77 \\
$50 / 50(0)$ & 1.19 & 3.48 \\
$50 / 50(2)$ & 0.81 & 2.77 \\
$50 / 50(5)$ & 0.58 & 2.07 \\
$50 / 50(10)$ & & 1.77
\end{tabular}

using the XRD: SIEMMENS D 5000 with radiations $\mathrm{Cu} \mathrm{K}$ alpha at $40 \mathrm{kV}$ and $30 \mathrm{Ma}$.

\section{Results and discussion}

The sorption data of different solvents into NR/NBR blend nanocomposites at different blend composition and filler loading with different solvents were determined. It is expressed as the molar percentage uptake (\% Qt) of solvent per gram of NR/NBR blends and was calculated using (Eq 1)

$\% Q_{t}=\frac{\frac{M t-M o}{M w}}{M_{o}} \times 100$.

$\mathrm{M}_{\mathrm{t}}$ is the mass of the sample at time $\mathrm{t} M_{o}$ is the initial mass of the sample and $M w$ is the molecular weight of the solvent. The molar percentage uptake $\left(\% \mathrm{Q}_{t}\right)$ for the solvent was plotted against the square root of time $(\sqrt{ } t)$. The sorption curves $(\%$ Qt moles of solvent sorbed per $100 \mathrm{~g}$ of rubber vs. $\sqrt{ } \mathrm{t})$ are shown in Figs. 1 and 2. The diffusion of solvent through a composite depends on the geometry of the filler (size, shape, size distribution, concentration and orientation), properties of the matrix and interaction between the matrix and filler.

Effect of blend composition

A significant initial increase in uptake was shown for the entire blend nanocomposite studied. This is due to the high concentration gradient of solvent molecules with the 
(a)

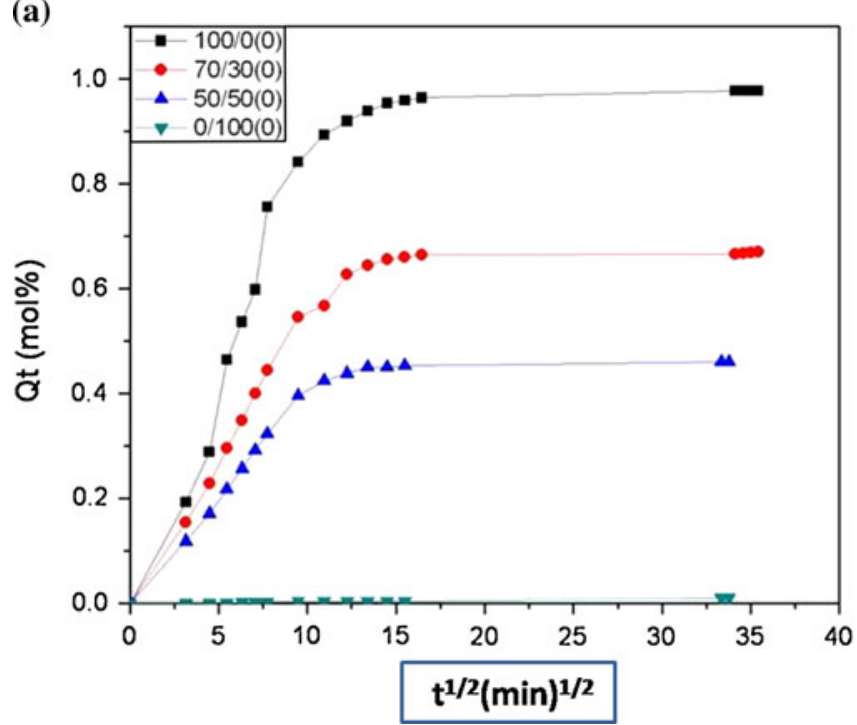

(b)

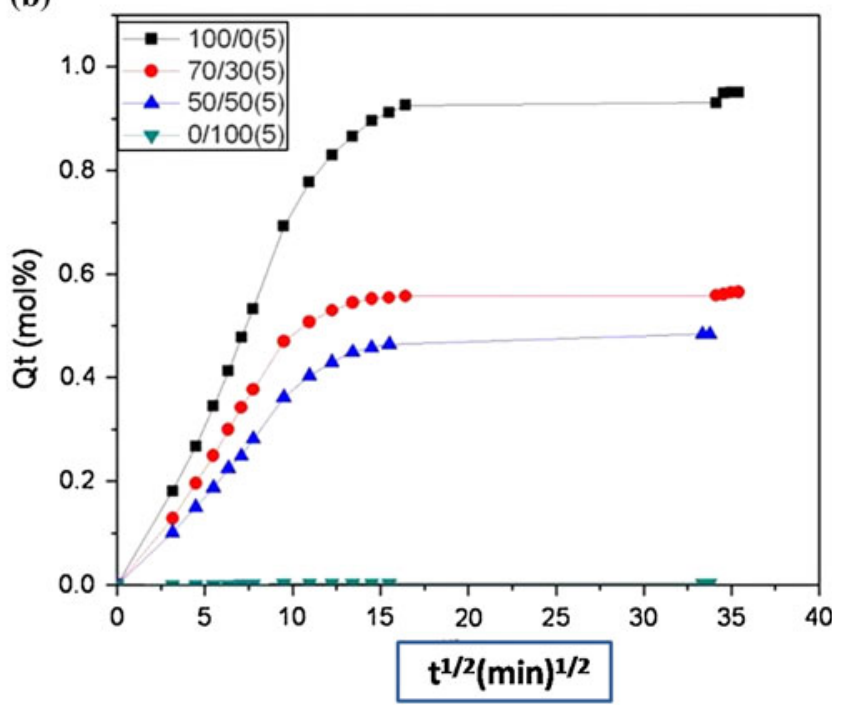

Fig. $1 \%$ Qt versus $\sqrt{ } \mathrm{t}$ of different NR/NBR blends in hexane a at zero loading $\mathbf{b}$ at $5 \%$ loading

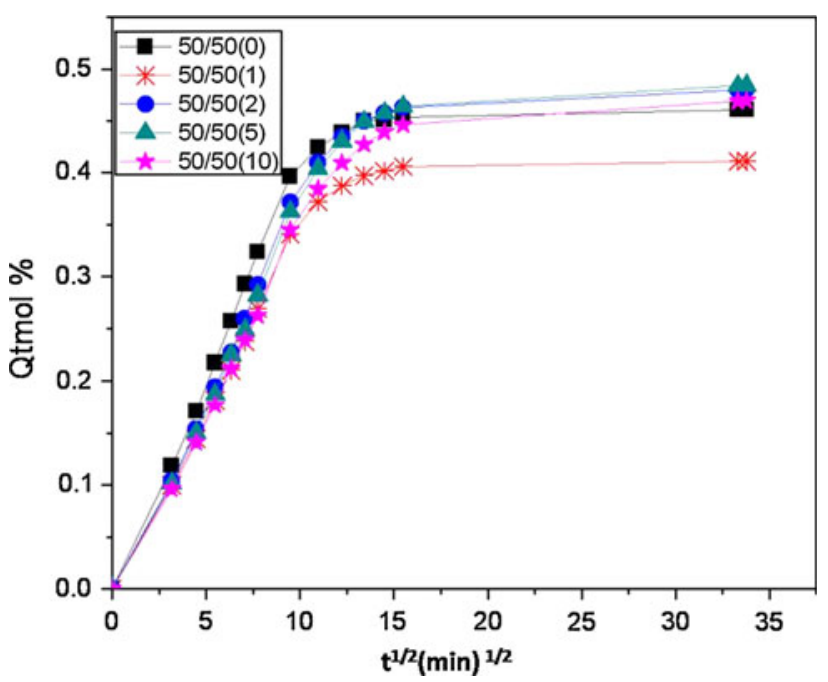

Fig. $2 \%$ Qt versus $\sqrt{ } \mathrm{t}$ of $50 / 50, \mathrm{NR} / \mathrm{NBR}$ blends nanocomposites in hexane with different clay loading

polymer. Also this initial solvent absorption rates in polymers have been explained in terms of rapid cavitations, which expose a greater surface area, thus enhancing solvent percolation [15]. On the other hand, after a time period of $24 \mathrm{~h}$ at equilibrium, the solvent uptake is counter balanced by solvent release from the polymer. From both Fig 1a, b, it is observed that NBR has the lowest equilibrium uptake. Also there is a decrease in the equilibrium uptake with the increase in NBR content. This is due to the high resistance of NBR to gas, organics and oil and also due to the higher cohesive energy of NBR. Difference in solubility parameters between the matrix and solvent is another reason for the decreased permeability in NBR (Table 1). The uptake was fastest in pure NR followed by 70/30 and 50/50 NR/NBR blends. The preferential migration of OMt towards NBR due to its polarity match further enhanced the solvent resistance for the blend composition with higher NBR content. These layers increase the path length for diffusion of solvent molecule to pass through the polymer. The increased path length predicted better barrier properties for nanocomposites. The uptake of solvent could be practically neglected for neat NBR and for nanocomposites of NBR. The same trend was also shown for the filled nanocomposites with pure NBR.

\section{Effect of clay loading}

For the given blend nanocomposites, the solvent uptake was found reduced with increased OMt content (Fig. 2). There is a decrease in solvent uptake with increase in filler loading up to $1 \mathrm{phr}$. This can be explained based on the fact that the local mobility of the polymer even after vulcanization [16] gets restricted by reinforcement of nanofillers and improves the solvent resistance. Thus, the reinforcement of blend by nanofiller improves the solvent resistance to a good extent. The diffusion of the penetrant solvent also depends on the concentration of free space available in the matrix to accommodate the penetrant molecule. The addition of OMt reduces the availability of free spaces (Fig.3a, b) and also creates a tortuous path for transport of solvent molecules. The uptake of solvent molecules was thus reduced for OMt filled composites compared to unfilled rubber. However, after filler loading of 1 and 2 phr there was an increase in solvent uptake. The mechanical properties (Figs. 4 and 5) also show the reinforcement at lower filler loading of nanoclay. But at higher loading there is a decrease in mechanical properties. This can be a result of the exfoliated morphology of the blend nanocomposite which is confirmed 
from the XRD data given in Fig. 6. The nanocomposites with 1 and 2 phr clay loading is predominantly exfoliated and enhanced the polymer/filler interactions. The intercalated and exfoliated morphology of the blend nanocomposites hinders the movement of penetrant molecules. Hindered movement of the penetrant molecules in the presence of $\mathrm{OMt}$ platelets are already reported [4]. The TEM image in Fig (7) further clarifies this, showing an exfoliated morphology at lower loading and agglomerated OMt at higher loading.

Effect of solvent

On comparing the two aromatic solvents, (Fig. 8) there is a decrease in solvent uptake when xylene is used as the solvent. The solubility parameter difference between the blend nanocomposites and the solvents varied with the solvents used. Hexane having a larger difference in solubility parameter from the blend nanocomposites showed lesser

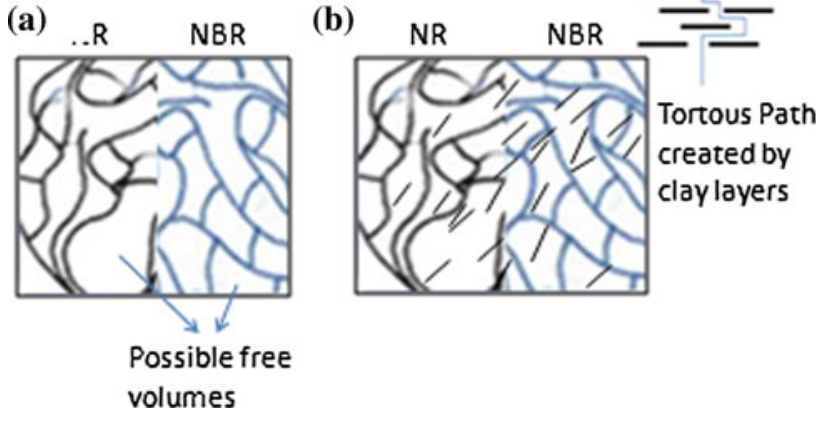

Fig. 3 Schematic showing a NR/NBR blend without OMt b with OMt

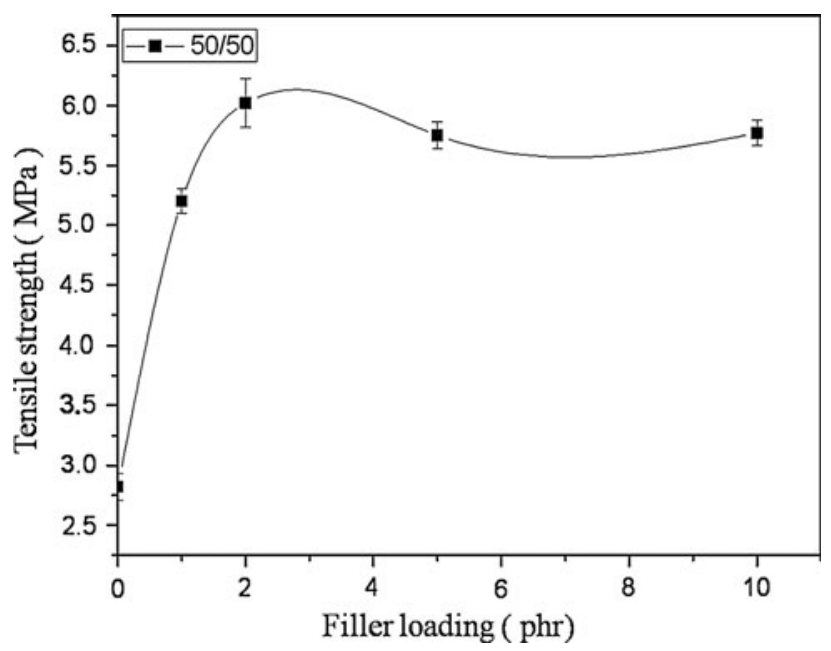

Fig. 4 Tensile strength of 50/50 NR/NBR blend nanocomposite with different clay loading diffusion compared to other solvents. The increase in molecular size of the penetrant-xylene molecule, rather than that of toluene $[17,18]$ also contributes to the lesser diffusion. The extremely low penetration of hexane compared with that of aromatic solvents can be attributed towards the higher molar volume of hexane compared to the two aromatic solvents [19] (Table 1). For each blend nanocomposite diffusion decreases when the solvent is hexane. Figure 9 shows the difference in solubility parameter values of the solvent with that of the blend nanocomposites. The plot of solubility parameter versus swelling of elastomers was made based on the concept that materials with similar solubility parameter mix well while swelling of polymers in solvents with very high difference in solubility parameter can be considered negligible. We have plotted the equilibrium swelling of selected blend nanocomposites against the resultant solubility parameter determined by Eq. (2) where $\Phi_{\mathrm{NR}}, \Phi_{\mathrm{NBR}}, \delta_{\mathrm{NR}}$, and $\delta_{\mathrm{NBR}}$ are the volume fraction and

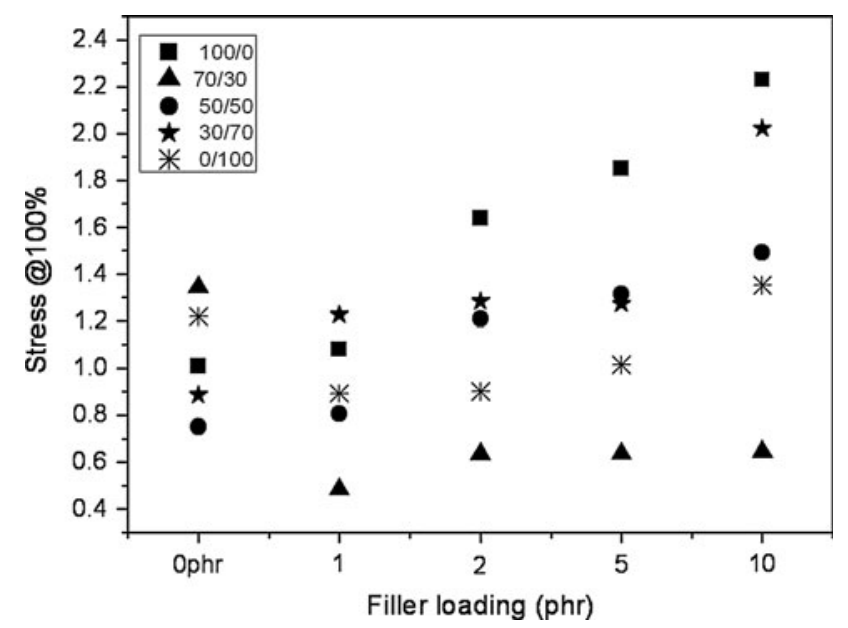

Fig. 5 Modulus value for 50/50 NR/NBR blend at different filler loading

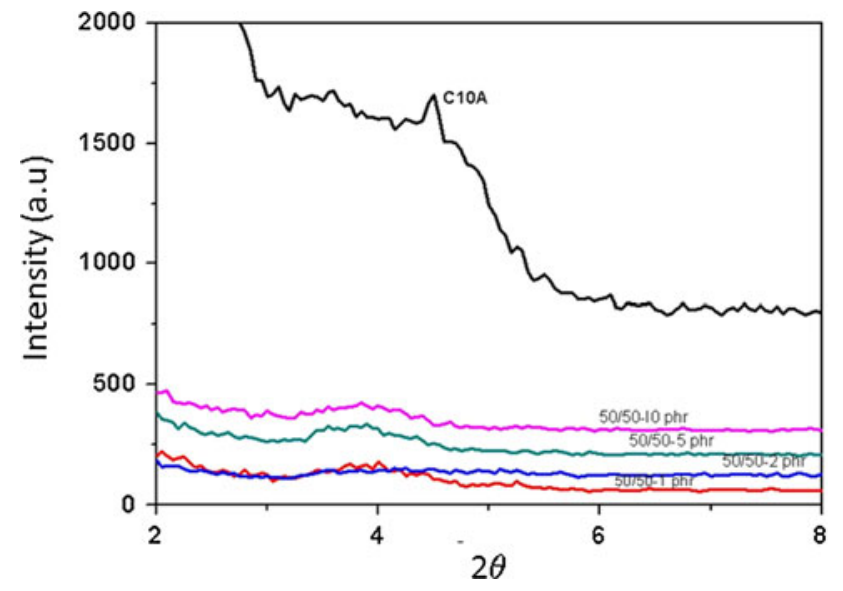

Fig. 6 XRD pattern for 50/50 NR/NBR blend at different filler loading 

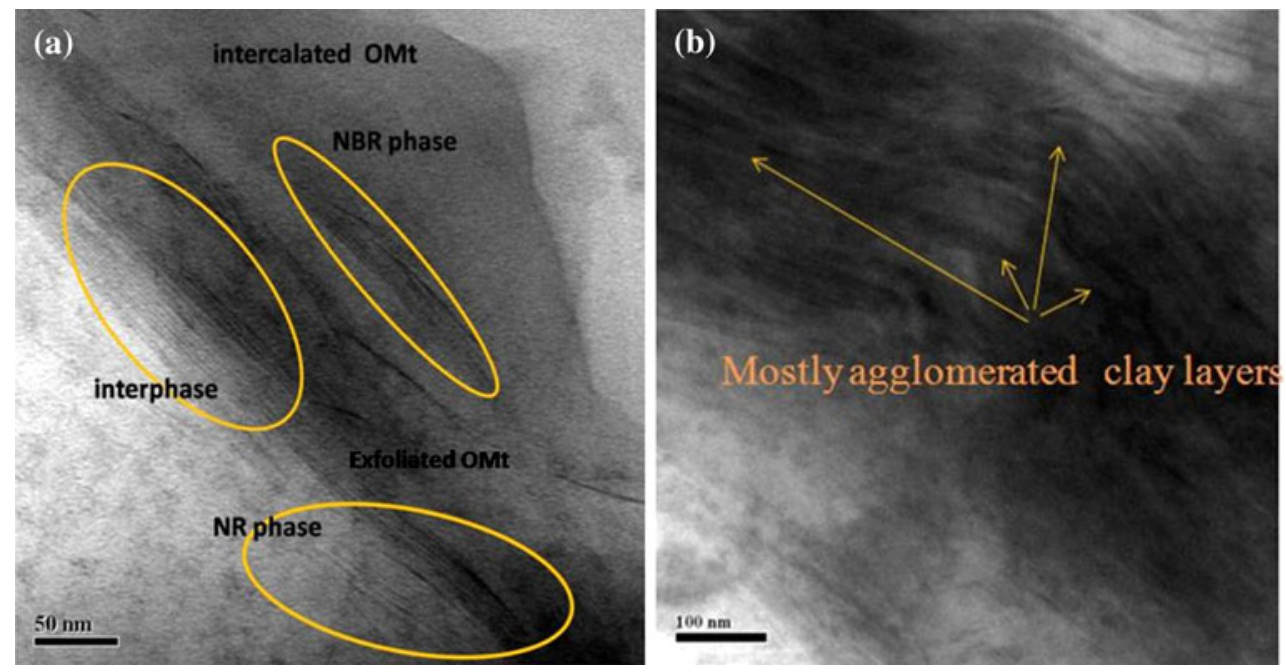

Fig. 7 TEM images of NR/NBR (clay) nanocomposites, a 50/50 (2) b 50/50 (10)

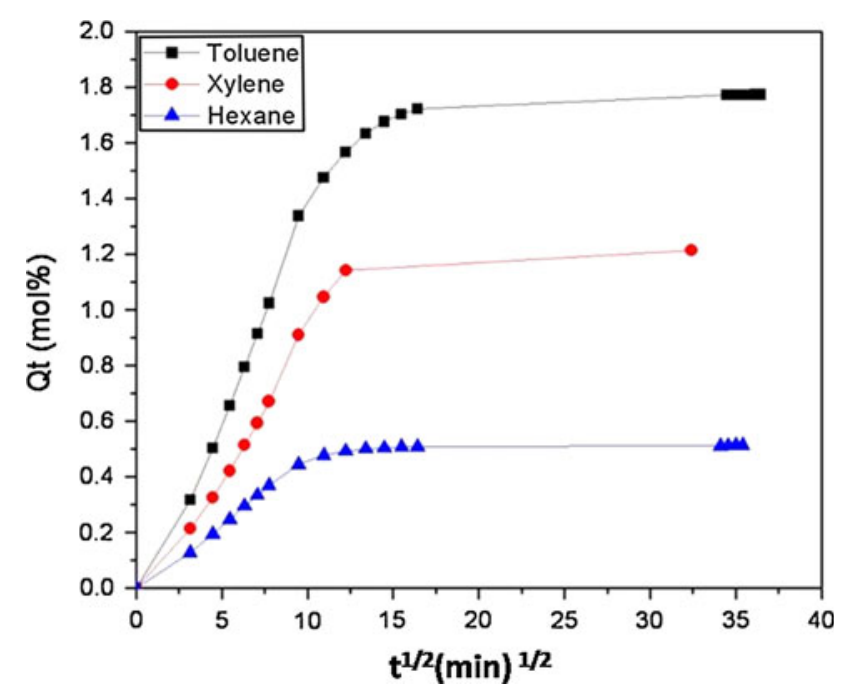

Fig. $8 \%$ Qt versus $\sqrt{ } \mathrm{t}$ of 70/30(1), NR/NBR blends nanocomposite with different solvents

solubility parameter of NR and NBR, respectively. The plot clearly explains the trend that as the value of $\delta$ s lies away from that of the polymer blends system it produces a very small change in equilibrium swelling. For hexane, the $\delta$ s (14.4) value is much different from that for the blend system ( $\sim 18)$ and the equilibrium swelling is very low when hexane is used as the solvent. Table 4 gives the difference in solubility parameter values of the solvent with that of the equilibrium uptake and, it can be seen that as the solubility parameter difference increases the equilibrium swelling decreases.

$\delta_{\text {effective }}=\Phi_{\mathrm{NR}} \cdot \delta_{\mathrm{NR}}+\Phi_{\mathrm{NBR}} \cdot \delta_{\mathrm{NBR}}$.

The plot of interaction parameter vs equilibrium uptake also shows that for hexane the equilibrium swelling

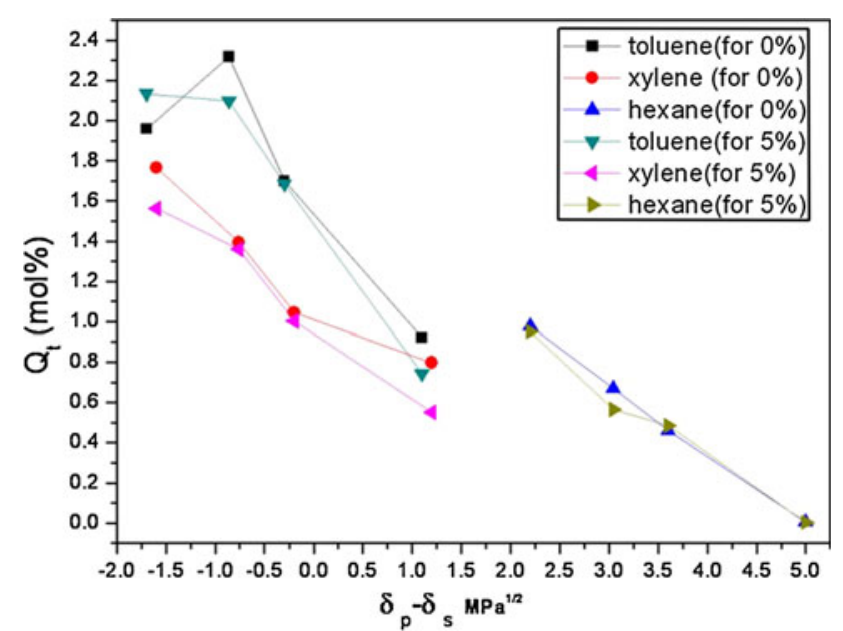

Fig. 9 Plot of solubility parameter versus equilibrium uptake in three solvents for different NR/NBR nanocomposites with 0 and 5 phr clay loading

decreased with increase in interaction parameter value. The interaction parameter $\chi$ expressed as a function of $\delta_{\mathrm{A}}$ and $\delta_{\mathrm{B}}$ denote the solubility parameters of the polymer blend system and of the solvent, respectively, by Eq. (3)

$\chi=\frac{V r}{R T} \times\left(\delta_{A}-\delta_{B}\right)^{2}$.

Mode of transport

The mechanism of transport can be computed from the diffusion data using Eq. (4) [20]

$Q_{t} / Q_{\infty}=k \cdot t^{n}$

where $k$ indicates the interaction between the penetrant and the polymer and $n$ represents the mode of transport. Taking $\log$ on both the sides, we get Eq. (5) [21]. The value of $n$ 
Table 4 The change in equilibrium uptake with solubility parameter difference

\begin{tabular}{|c|c|c|c|c|c|}
\hline & 0 & 1 & 2 & 5 & 10 \\
\hline \multicolumn{6}{|c|}{$\delta \mathrm{p}-\delta \mathrm{s}$ (Toluene) } \\
\hline 1.6 & 1.76 & 1.40 & 1.55 & 1.56 & 1.87 \\
\hline 0.7 & 1.39 & 1.21 & 1.31 & 1.35 & 1.39 \\
\hline 0.2 & 1.04 & 1.02 & 1.10 & 1.002 & 1.13 \\
\hline 1.2 & 0.79 & 0.52 & 0.53 & 0.55 & 0.49 \\
\hline \multicolumn{6}{|c|}{$\delta \mathrm{p}-\delta \mathrm{s}$ (Xylene) } \\
\hline 1.7 & 1.95 & 1.85 & 1.99 & 2.13 & 2.39 \\
\hline 0.8 & 2.31 & 1.77 & 2.27 & 2.09 & 2.59 \\
\hline 0.3 & 1.69 & 1.45 & 1.21 & 1.68 & 1.83 \\
\hline 1.1 & 0.92 & 0.81 & 0.86 & 0.74 & 1.17 \\
\hline \multicolumn{6}{|c|}{$\delta \mathrm{p}-\delta \mathrm{s}$ (Hexane) } \\
\hline 2.2 & 0.97 & 0.79 & 0.90 & 0.95 & 0.98 \\
\hline 3.0 & 0.66 & 0.51 & 0.49 & 0.56 & 0.92 \\
\hline 3.6 & 0.46 & 0.41 & 0.48 & 0.48 & 0.46 \\
\hline 5.0 & 0.005 & 0.002 & 0.004 & 0.003 & 0.005 \\
\hline
\end{tabular}

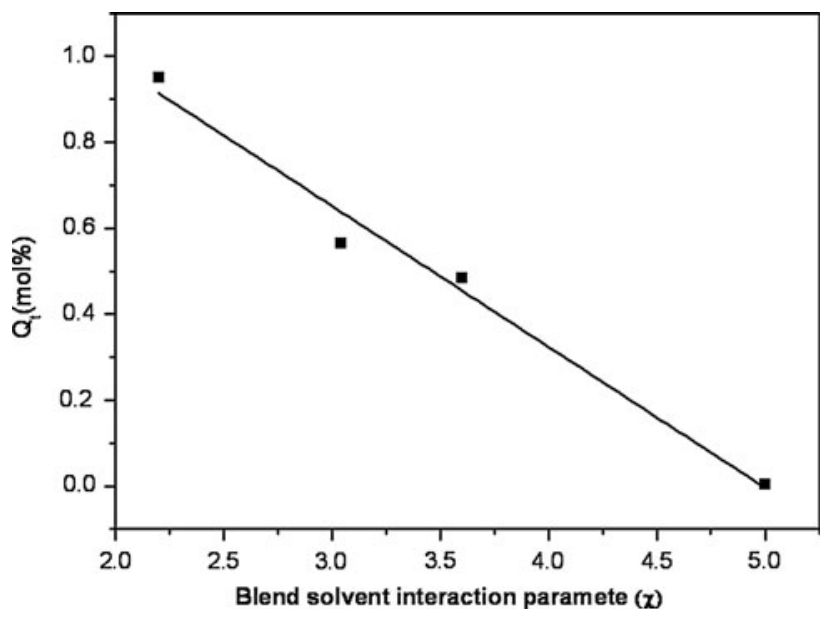

Fig. 10 Plot of interaction parameter versus equilibrium uptake in three solvents for different NR/NBR nanocomposites with $5 \mathrm{phr}$ clay loading

and $k$ are obtained from the slope and intercept of plot of $\log Q_{\mathrm{t}} / Q_{\infty}$ (Eq. 5)

$\log Q_{t} / Q_{\infty}=\log k+n \log \mathrm{t}$

and is given in Table 5. For normal Fickian mode of transport, where rate of polymer chain relaxation is higher compared to the diffusion of penetrant, an $n$ value of approximately 0.5 have been reported. [22] The Fickian diffusion, actually, refers to a situation where solvent penetration is less than the polymer chain relaxation. When $n=1$, the transport approaches non-Fickian behaviour, where chain relaxation is slower than the liquid penetration. If the value of $\mathrm{n}$ is in between 0.5 and 1 , the mode of
Table 5 Values of $\mathrm{n}$ and $\mathrm{k}$ for different clay loading of NR/NBR blend nanocpmposites

\begin{tabular}{lll}
\hline Composition & $n$ & $k$ \\
\hline $70 / 30(0)$ & 0.68 & 1.2 \\
$70 / 30(1)$ & 0.68 & 1.19 \\
$70 / 30(2)$ & 0.65 & 1.13 \\
$70 / 30(5)$ & 0.69 & 1.25 \\
$70 / 30(10)$ & 0.68 & 1.35 \\
$50 / 50(0)$ & 0.56 & 1.15 \\
$50 / 50(1)$ & 0.54 & 1.15 \\
$50 / 50(2)$ & 0.56 & 1.23 \\
$50 / 50(5)$ & 0.56 & 1.24 \\
$50 / 50(10)$ & 0.56 & 0.93 \\
\hline
\end{tabular}

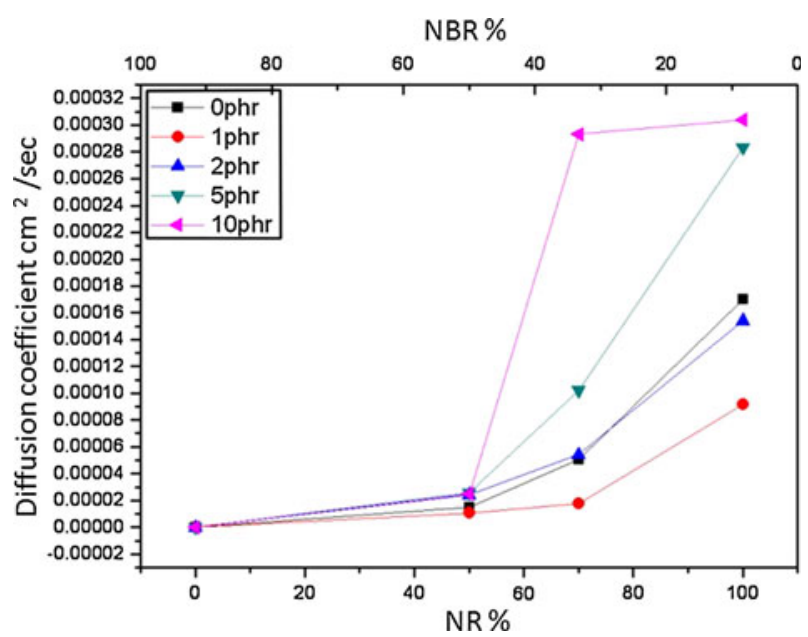

Fig. 11 Diffusion coefficient in hexane for different blend nanocomposites with different phr clay loading

transport is classified as anomalous. Nevertheless, when the solvent penetration is much below the polymer chain relaxation, it is possible to record the $\mathrm{n}$ values below 0.5 . This situation, which is still regarded as Fickian diffusion, is named 'Less Fickian' [20], or quasi Fickian. This mechanism indicates that the solvent diffuses slowly through the swollen matrix and free spaces in the nanocomposite sample [23]. The estimated values of $n$ and $k$ for $70 / 30$ and 50/50 blend nanocomposites are given in Table 5. With a change in blend composition the value of $n$ varies from Fickian diffusion into an anomalous transport of the penetrant molecules. Anomalous transport occurs due to the coupling of Fickian and non-Fickian transport mechanisms. Variation from Fickian sorption is associated with the time taken by rubber segments to respond to swelling stress and rearrange them to accommodate the solvent molecules [4]. The reinforcement with the filler particle imparts a high degree of restriction to the rearrangement of rubber chains. Both NR and NBR chains gets 
restricted due to the interaction of the OMt. While, the interaction between NBR is due to the polarity factors, the NR phase also shows some interaction with the OMt due to the presence of HT which is rich in alkyl groups. Thus, the observed anomalous diffusion can be because of the counteraction between the ability of rubber segments to rearrange in the presence of solvents and the restriction imparted to this by the reinforced filler particles. The $k$ values decrease for lower filler loading, indicating less diffusion. 'The value of $k$ indicates the degree of rubber interactions with the solvent. When polymer -filler interaction is good or when there is good dispersion of filler in the polymer there will be less interaction between the solvent and the polymer. The higher difference in solubility parameter value also decreases the interaction of the solvent with the blend system'.

\section{Diffusion coefficient (D)}

The diffusion coefficient or the diffusivity $\mathrm{D}$ of a solvent molecule through a polymer membrane can be calculated using Eq. (6) obtained using Fickian's second law [24, 25],

$D=\left(h \theta / 4 Q_{\infty}\right)^{2}$,

where $h$ is the blend thickness, $\theta$ is the slope of the initial linear portion of the plot of $\% Q t$ against $\sqrt{ } t$, and $Q \infty$ is the equilibrium absorption. As we increase the NBR content, the diffusion coefficient decreases (Fig. 11) because of the high resistance of NBR to gas, organics and oil. NBR is having high cohesive energy density because of the functional groups present in it. Therefore, the blend nanocomposites exhibit lower diffusivity value at higher NBR content. And it has been reported that the presence of polar or bulky groups also influence the diffusion properties [26]. The sluggish motion of the polymer chains caused

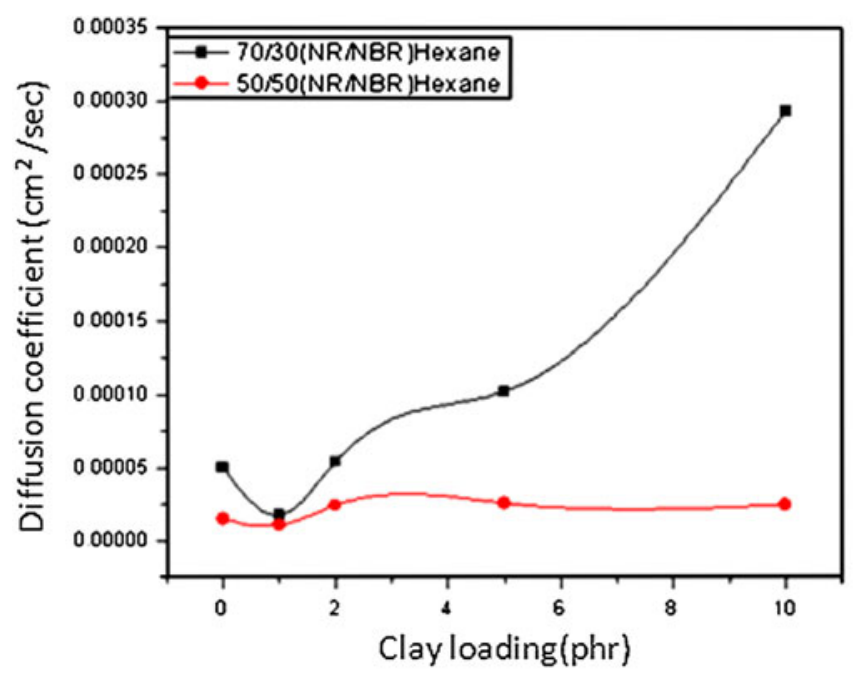

by the presence of nitrile group in NBR can be another reason for the low permeability.

The addition of OMt will reduce the availability of spaces 374 and restrict the mobility of chain segments. On analyzing the blend nanocomposites with different clay loading, a sharp decrease in diffusion coefficient for 50/50 NR/NBR blend with $2 \mathrm{phr}$ is observed. This can be attributed towards the exfoliated morphology of the blend nanocomposite which is confirmed from the XRD data given in [Fig. 6]. While the d-spacing was found to be $19.6 \AA$ for neat clay. The value was shifted to $23.42 \AA$ for 5 and 10phr OMt, where an intercalated morphology was observed. Thus, the nanocomposites with 1 and 2 phr clay loading were predominantly exfoliated and for 5 and $10 \mathrm{phr}$ it was intercalated. The intercalated and exfoliated morphology of the blend nanocomposites hinders the movement of penetrant molecules. The TEM images of 2 and $5 \mathrm{phr}$ also confirm this. Hindered movement of the penetrant molecules in the presence of nanoclay platelets are already reported [4, 10]. The comparatively less rate of diffusion coefficient value for 1 and 2 phr explains the better dispersion of clay at this compositions.

On comparing the diffusion coefficient for two solvents Fig 12, there is a decrease in diffusion coefficient by changing the solvent from toluene to hexane for every system. Also this can be attributed towards the higher molecular volume of hexane and its higher solubility parameter difference with the polymer. (Table 1) [14]. The solubility parameter of hexane shows good difference from that of NR and NBR, while for toluene it is nearer to the solubility parameter value of both the rubbers. Diffusivity is thus greatly dependent on the size and solubility parameter of the penetrant molecules. Many investigators [17, 18] have reported a decrease in equilibrium penetrant uptake with increasing penetrant chain length. The shape of penetrant also plays a role in determining diffusion.

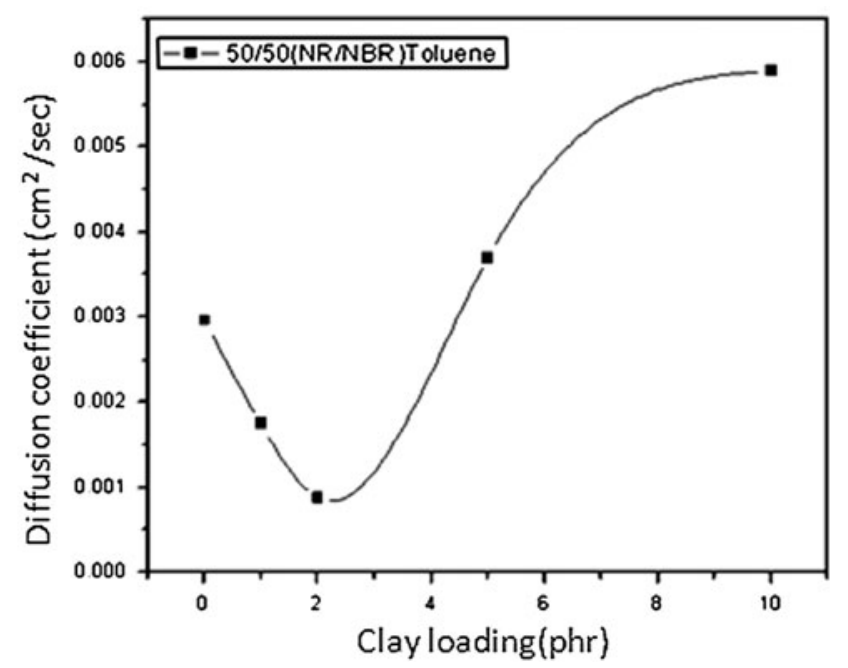

Fig. 12 Diffusion coefficient in hexane and toluene for 50/50 and 70/30 blend with different clay loading 
Table 6 Values of permeation coefficient

\begin{tabular}{lccc}
\hline NR/NBR & Clay $\%$ & \multicolumn{2}{c}{ Permeation coefficient $P^{*} 10^{-5}\left(\mathrm{~cm}^{2} / \mathrm{min}\right)$} \\
\cline { 3 - 4 } & & Hexane & Toluene \\
\hline $100 / 0$ & 0 & 4.15 & 10.88 \\
$70 / 30$ & 0 & 9.99 & 35.68 \\
$50 / 50$ & 0 & 2.58 & 10.06 \\
$0 / 100$ & 0 & $1.5 \times 10^{-6}$ & 0.902 \\
$100 / 0$ & 5 & 61.8 & 25.0 \\
$70 / 30$ & 5 & 18.9 & 24.1 \\
$50 / 50$ & 5 & 3.91 & 11.1 \\
$0 / 100$ & 5 & $6.4 \times 10^{-8}$ & 033 \\
$50 / 50$ & 0 & $5 .-20$ & 5.07 \\
$50 / 50$ & 1 & 3.26 & 3.86 \\
$50 / 50$ & 2 & 7.40 & 1.36 \\
$50 / 50$ & 5 & 7.81 & 8.06 \\
$50 / 50$ & 10 & 7.61 & 13.10 \\
\hline
\end{tabular}

Permeability coefficient $(\mathrm{P})$

The permeability coefficient $(P)$ of toluene in the rubber blends was obtained as follows [27]:

$P=D * S$,

where $D$ is the diffusion coefficient and $S$ is the sorption coefficient.

The values of $P$ are shown in Table 6. For both aliphatic and aromatic solvents, the same trend was shown but the magnitude was different due to the difference in penetrant properties. For different NR/NBR blends with $5 \%$ filler loading, it was shown that the permeation coefficient decreases on adding filler which can be well-explained due to the tortuous path that the clay have made in the blend. While its strong polarity match influences the migration towards NBR the presence of HT causes the clay to migrate towards the NR phase and to the interface. The presence of clay at the interface, and in both the NR and NBR phases hinders the movement of solvent molecules. For 50/50 blends with different clay loading, at $1 \%$ loading permeability of aliphatic penetrant increases while for aromatic it increases at $2 \%$ loading. This, as discussed earlier was found to be related to the structural difference between the two penetrant molecules and the diffusion path in the polymer intercalated clay network, which paves way for the hexane molecule to penetrate easily at $2 \%$ loading. Thus, it was shown that permeability followed the same trend as the diffusion coefficient and that diffusion process controls the permeability.

Swelling parameters

In order to assess the blends reinforced with OMt, the swelling coefficients $(\beta)$ have been calculated by Eq. (8). The extent of swelling, interface strength and degree of dispersion of fillers in the elastomer matrix can be inferred from the swelling parameter value [28, 29]. The extent of swelling behaviour of the blend nanocomposites were inferred from the swelling parameters like swelling index, swelling coefficient etc. Swelling coefficient is an index of the ability with which the sample swells. The swelling behaviour of the blend nanocomposites was assessed (Table 7) using Eq (8) [30].

swellingcoefficent $\beta=\left(M_{\infty}-M_{0}\right) / M_{0} \times \rho_{s}$,

where $M_{\mathrm{o}}$ and $M_{\infty}$ are mass of the sample before and after swelling, respectively, and $\rho_{\mathrm{s}}$ is the density of the solvent. Swelling index which is another parameter of transport properties is calculated by the Eq. (9)

Table 7 Mol. wt bet. cross-link, Mc, cross-link density, swelling coefficient and swelling index of the NR/NBR blend nanocomposites

\begin{tabular}{|c|c|c|c|c|c|c|c|}
\hline \multirow[t]{2}{*}{ NR/NBR } & \multirow[t]{2}{*}{ Clay $\%$} & \multirow[t]{2}{*}{ Mc (g/mole) } & \multirow[t]{2}{*}{ v (mole/cc) X10-4 } & \multicolumn{2}{|c|}{ Swelling coefficient $\beta$} & \multicolumn{2}{|c|}{ Swelling index $\%$} \\
\hline & & & & Toluene & Hexane & Toluene & Hexane \\
\hline $100 / 0$ & 0 & 951.3 & 5.26 & 3.3 & 2.1 & 288.69 & 144.4 \\
\hline $70 / 30$ & 0 & 1111.8 & 4.50 & 3.9 & 1.5 & 342.87 & 99.80 \\
\hline $50 / 50$ & 0 & 830.2 & 6.02 & 2.8 & 1.0 & 247.01 & 72.08 \\
\hline $0 / 100$ & 0 & 446.0 & 11.21 & 1.2 & 0.008 & 107.08 & 00.56 \\
\hline $100 / 0$ & 5 & 852.8 & 5.86 & 2.9 & 1.7 & 254.85 & 118.4 \\
\hline $70 / 30$ & 5 & 976.0 & 5.12 & 3.4 & 1.3 & 297.12 & 85.95 \\
\hline $50 / 50$ & 5 & 705.1 & 7.09 & 2.3 & 0.8 & 202.98 & 56.56 \\
\hline $0 / 100$ & 5 & 426.4 & 11.72 & 1.1 & 0.006 & 99.481 & 00.40 \\
\hline $50 / 50$ & 0 & 830.2 & 6.02 & 2.8 & 1.09 & 247.01 & 72.08 \\
\hline $50 / 50$ & 1 & 702.4 & 7.12 & 2.3 & 0.8 & 202.04 & 55.26 \\
\hline $50 / 50$ & 2 & 713.6 & 7.01 & 2.3 & 0.8 & 206.01 & 55.84 \\
\hline $50 / 50$ & 5 & 705.1 & 7.09 & 2.3 & 0.8 & 202.98 & 56.56 \\
\hline $50 / 50$ & 10 & 713.3 & 7.01 & 2.3 & 0.8 & 205.92 & 55.40 \\
\hline
\end{tabular}


swellingindex $\%=\left(M_{\infty}-M_{0}\right) / M_{0} \times 100$

The values of swelling coefficient (Table 7) decreases to a good extent with filler loading. This is can be attributed towards the presence of fillers that hinders the path of penetrant molecules to an otherwise free path i.e. in the pure NR phase.

\section{Cross-link density}

The cross-link density can be determined from equation

Crosslinkdensity, $v=1 / 2 M_{c}$,

where $\mathrm{M}_{\mathrm{c}}$ by the molecular weight between two successive crosslinks and is determined by Eq. (11)

$M_{c}=-\frac{\left(\rho_{r} V_{S} \varphi_{r}^{\frac{1}{3}}\right)}{\ln (1-\varphi)+\varphi_{r+\chi \phi^{2}}}$

where $\rho_{\mathrm{r}}$ is the density of rubber, $\mathrm{V}_{\mathrm{s}}$ is the molar volume of solvent absorbed (toluene $V_{\mathrm{o}}=106.3 \mathrm{~cm} \mathrm{3/mole);} \varphi r f$ is the volume fraction of the rubber in the swollen material. $\varphi r f$ is given by the Eq. (12) of Ellis and Welding [32]

$\varphi_{r f}=\frac{\left(\frac{d-f w}{\rho_{p}}\right)}{\left(\frac{d-f w}{\rho_{p}}\right)+A_{s} / \rho_{s}}$,

where $d$ is the deswollen weight, $\mathrm{f}$ is the volume fraction of the filler, $w$ is the initial weight of the sample, $\rho_{\mathrm{p}}$ is the density of the polymer, $\rho_{\mathrm{s}}$ the density of solvent and $\mathrm{A}_{s}$ is the amount of solvent absorbed. $\chi$ the interaction parameter i.e. the Flory-Huggins polymer-solvent interaction term was calculated from the Hildebrand Eq. (13) [33]

$\chi=\beta+\frac{V_{s}\left(\delta_{s}-\delta_{p}\right)^{2}}{R T}$,

where $\beta$ is the lattice constant, $V \mathrm{~s}$ is the molar volume, $R$ is the universal gas constant, $T$ is the absolute temperature, $\delta_{s}$ and $\delta_{p}$ are solubility parameter of the solvent and polymer respectively.

The calculated result of molecular mass $\left(M_{\mathrm{c}}\right)$ and the cross-link density $v$ are listed in Table (8). As we increase the NBR content in the blends a decreasing tendency for $M_{\mathrm{c}}$ is observed. This may be attributed to the difference in nature of the two elastomers [34]. The slight increase in cross-link density with NBR content indicates the better reinforcing effect of polar cloisite 10A with NBR matrix. This reinforcement due to better interaction between polymer and clay, reduces the penetration of solvent molecules. The schematic in Fig. 13a, b shows how the filler at lower concentration reduces the penetration by forming a network and how at high concentration the clay agglomerates together reducing the interaction between clay and polymer.
Table 8 Values of $M_{c}(\operatorname{Exp}) . M_{c}(p h)$.and $M_{c}$ (aff).in $\mathrm{g} / \mathrm{cm}^{3}$

\begin{tabular}{llll}
\hline & $\mathrm{M}_{\mathrm{c}}(\mathrm{Exp})$ & $\mathrm{M}_{\mathrm{c}}(\mathrm{Ph})$ & $\mathrm{M}_{\mathrm{c}}$ (Aff) \\
\hline Hexane & & & \\
50/50 (0) & 103.5 & 389.0 & 50.9 \\
$50 / 50(1)$ & 113.3 & 327.7 & 44.7 \\
$50 / 50(2)$ & 112.9 & 329.7 & 44.9 \\
$50 / 50(5)$ & 112.4 & 332.2 & 45.1 \\
$50 / 50(10)$ & 113.2 & 328.2 & 44.7 \\
Toluene & & & \\
$50 / 50(0)$ & 401.9 & 959.9 & 79.5 \\
$50 / 50(1)$ & 350.5 & 837.0 & 67.2 \\
$50 / 50(2)$ & 355.0 & 847.8 & 68.3 \\
$50 / 50(5)$ & 351.5 & 839.5 & 67.5 \\
$50 / 50(10)$ & 354.9 & 847.6 & 68.3 \\
\hline
\end{tabular}

To compare with the theory, the molecular weight between the cross links was compared with the affine limit of the model $[\mathrm{Mc}(\mathrm{aff})]$ and the phantom network model proposed by James and Guth using the equation [35, 36] Eqs. (14) and (15), respectively.

$M c($ aff $)=\frac{\rho_{P} V \emptyset_{2 c}^{\frac{2}{3}} \emptyset_{2 m}^{\frac{1}{3}}\left(1-\frac{\mu}{v} \emptyset_{2 m}^{\frac{1}{3}}\right)}{\left(-\ln \left(1-\phi_{2 m}\right)+\phi_{2 m}+\chi \phi_{2 m}^{2}\right.}$

$M c(p h)=\frac{(1-2 / \chi) \rho_{P} V \emptyset_{2 c}^{\frac{2}{3}} \emptyset_{2 m}^{\frac{1}{3}}}{\left[-\ln \left(1-\phi_{2 m}\right)+\phi_{2 m}+\chi \phi_{2 m}^{2}\right]}$,

where $\mu$ and $v$ are the number of effective chains and junctions [37]. $\phi_{2 \mathrm{~m}}$ is the polymer volume fraction of swelling at equilibrium, and $\phi_{2 \mathrm{c}}$, the polymer volume fraction during crosslinking, where the chain may move freely through one another where $\chi$ is the junction functionality [38]. The calculated $M_{\mathrm{c}}$ values along with the experimental values are detailed in Table 8.

It was found that the $M c$ values of phantom network model showed moderate agreement with the experimental values rather than with the affine model. Here the chain can move freely through one another, i.e. the junction points fluctuate over time around their mean position without any hindrance from the neighbouring molecules.

Kinetic modelling of diffusion

The major objectives of mathematical modelling are the prediction of diffusion behaviour through polymers, optimization of the diffusion kinetics and elucidation of the physical mechanism of transport, by comparing diffusion data using mathematical models [39]. Here we have used the diffusion models like first-order kinetic equation, Higuchi model, Korsmeyer Peppas model and Peppas-Sahlin equation to predict the diffusion behaviour. All these models are based on the process in which penetrants migrate from the 
Fig. 13 Schematic showing the clay network at lower loading and aggregates at higher loading (a)

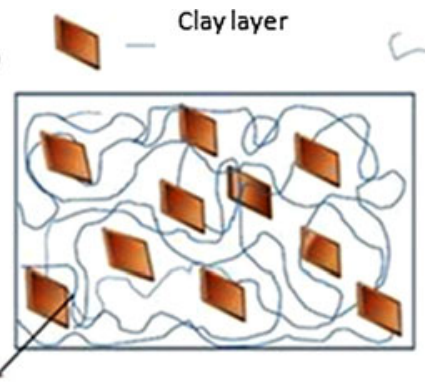

(b)

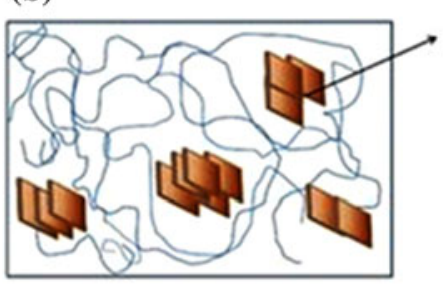

Clay layers forming a network with

polymer at lower filler loading making it

difficult for the solvent molecules to

diffuse

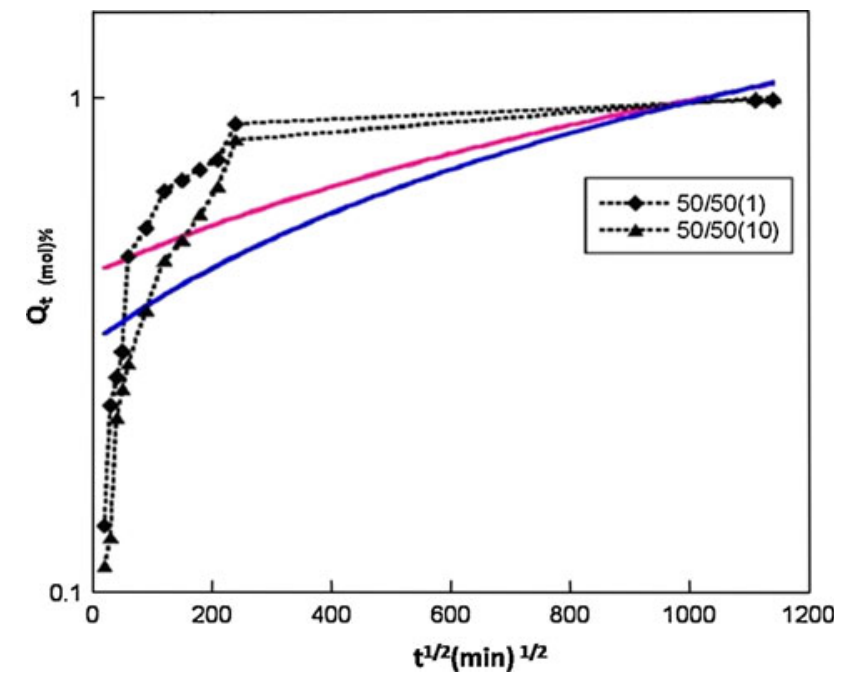

Fig. 14 Model fitting of the solvent permeation through NR/NBR blend nanocomposites using first-order Kinetics

initial position in the polymeric system to the polymer's outer surface [40]. This is affected by factors such as the physicochemical properties of the penetrant, the structural characteristics of the material system etc. Applying these models in polymeric system is thus justified. Also it has been reported that, penetrant diffusion and polymeric matrix swelling are suggested to be the main driving forces for transport of penetrants containing polymeric matrices. Specifically, Fick's law of diffusion provides the basis for the description of all these models. The equation and the corresponding fitting parameters are given in Table 6. Firstorder kinetics can be expressed by the Eq. (16) [41].

$\log \mathrm{Q}_{\mathrm{t}}=\log \mathrm{Q}_{\infty}-\mathrm{k}_{\mathrm{t}} / 2.303$,

where, $Q_{\infty}$ is the concentration of solvent at equilibrium, $k$ is the first-order rate constant and $\mathrm{t}$ is the time. The data obtained are plotted as $\log Q_{\mathrm{t}} / Q_{\infty}$ versus time (Fig 14). From the plot it is clear that the diffusion of solvent is not proportional to the amount remaining in the polymer matrix as the curve is not fitted well.

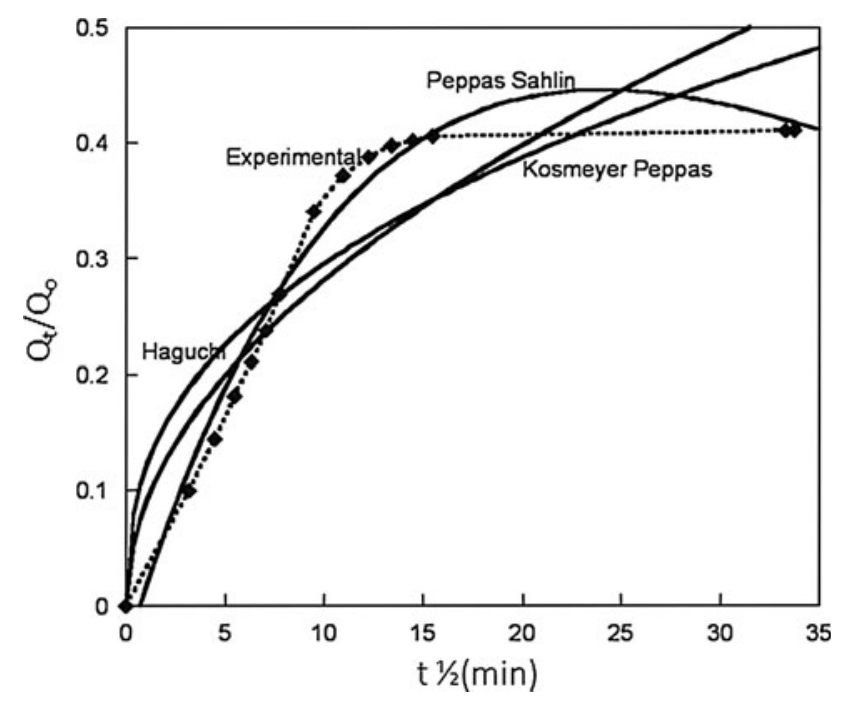

Fig. 15 Model fitting of the solvent permeation through NR/NBR blend nanocomposites using Peppas-Sahlin, Haguchi and KorsmeyerPeppas

Higuchi equation tries to relate the release rate based on simple laws of diffusion. The equation describes the release/diffusion processes under Fickian mechanism, or through non Fickian mechanism. In the case of Fickian mechanism, the rate of diffusion is much less than that of polymer relaxation. For Case II system or non Fickian, the rate of diffusion is much larger than that of polymer relaxation. The Higuchi model [41] is represented as:

$Q t=K_{h} * t^{1 / 2}$,

where $K_{\mathrm{h}}$ is the Higuchi dissolution constant, $\mathrm{t}$ is the time and $Q_{\mathrm{t}}$ is the molar percentage uptake. Power law equation is more comprehensive very simple and semi-empirical equation developed by Korsmeyer-Peppas [42]. From the equation it can be related that the fractional diffusion is exponentially related to diffusion time (Fig. 15). Another analysis mechanism that consider diffusion in polymer matrices as a result of two processes, i.e. diffusion into the 
Table 9 Correlation coefficient (R2) and constant (K) of different kinetic models

\begin{tabular}{|c|c|c|c|c|c|c|c|c|c|}
\hline \multirow[t]{2}{*}{ Formulation } & \multicolumn{2}{|c|}{ First order kinetics } & \multicolumn{3}{|c|}{ Peppas Sahlin model } & \multicolumn{2}{|c|}{ korsmeyer-Peppas model } & \multicolumn{2}{|c|}{ Haguchi model } \\
\hline & $\overline{\mathrm{R}^{2}}$ & $\mathrm{~K}_{1}$ & $\mathrm{R}^{2}$ & $\mathrm{~K}_{\mathrm{f}}$ & $\mathrm{K}_{\mathrm{r}}$ & $\mathrm{R}^{2}$ & $\mathrm{n}$ & $\overline{\mathrm{R}^{2}}$ & $\mathrm{k}$ \\
\hline NR/NBR 50/50(1) & 0.5579 & 0.0005 & 0.98155 & 0.0419 & -0.0003 & 0.8513 & 0.265 & 0.4667 & 0.0401 \\
\hline
\end{tabular}

swollen polymer and matrix relaxation This was carried out by fitting the data to the model proposed by Peppas and Sahlin (Eq.18) [43]

$M_{t} / M_{\infty}=K_{f} t^{m}+K_{r} t^{2 m}$

given by the above equation: where $M_{\mathrm{t}} / M_{\infty}$ is the fraction of solvent released at time $t, K_{\mathrm{f}}$ is the diffusion Fickian contribution coefficient, $K_{\mathrm{r}}$ is the relaxation contribution coefficient and $m$ is the purely Fickian diffusion exponent. When $K_{\mathrm{f}}>K_{\mathrm{r}}$ the release is mainly controlled by diffusion, when $K_{\mathrm{r}}>K_{\mathrm{f}}$, the diffusion is mostly due to matrix swelling. When $K_{\mathrm{f}}=K \mathrm{r}$, the diffusion is a combination of diffusion and polymer relaxation. The selection of the appropriate model to ensure the effectiveness can be found out from correlation coefficient $(R)$ (Table 9) and it is found that the experimental value fitted quite well into the model.

\section{Conclusions}

The transport properties of organically modified montmorillonite filled NR/NBR blends were investigated. The addition of layered structured nanofillers enhanced the barrier property of the elastomer blend nanocomposites. It was found that blend composition and clay loading played a significant role in determining the diffusion parameters like solvent uptake, diffusion and permeation coefficients. For neat polymer the diffusivity was high. Nevertheless, the presence of OMt showed lower diffusion at lower filler loading, due to the fine dispersion leading to good polymer/ filler interactions. The claim was supported by the XRD data, where an exfoliated morphology was shown. The mechanical properties also supported the diffusion behaviour of nanocomposites. The slower diffusion was associated with the increase in tortousity. At higher loading of OMt, overall diffusion was increased due to poor polymer/ filler interactions caused by OMt agglomeration. These assumptions tally with the observations from the TEM analysis. The shape and size of the solvent also played a considerable role in determining the diffusion parameters. The cross link density, an important characteristic, influencing the properties of cured rubber was also determined and an increase of the same was found at lower filler loading. The experimental values were fitted with mathematical models, and showed rather fine agreement with theoretical values. Among the mathematical models used for determining the molecular weight between the crosslinks, the phantom model shows more agreement with the experimental values. At the same time., Kinetics of diffusion fitted well for Peppas Sahlin model, where diffusion was considered to be a combination of Fickian diffusion and polymer relaxation process.

\section{Highlights}

- Addition of fillers could create hindered path for solvents molecules to diffuse.

- Better dispersion at lower filler loading with a decrease in diffusion .

- Good correlation between TEM, XRD and mechanical property could be deduced.

- The experimental data of transport studies were compared with theoretical values.

Acknowledgements The authors would like to thank Department of Science \& Technology (DST)-Nano Science and Technology (Nano Mission), Delhi, India for the financial support. Jozef Stefan Institute, Department F4 Jamova Cesta 39 SI-1000 Ljubljana, Slovenia for support and guidance, Ecole de mine Albi for SEM and XRD measurements. English India clay, Thiruvanthapuram, Kerala, India for providing nanoclay and ELIOKEM India Pvt. Ltd, for providing NBR.

\section{References}

1. Chainey M (1989) In: Cheremisinoff NP (eds) Handbook of polymer science and technology, composites and specialty applications, Marcel Dekker, New York, 499-540

2. Koros WJ (1990) Barrier polymers and structures, ACS Symp. Ser, vol 423. American Chemical Society, Washington DC, pp 1-21

3. Kraus GJ (1963) J Appl Polym Sci 7:861-871

4. Barrer RM, Barrie JA, Rogers MG (1963) J Polym Sci Part A 8:2565-2586

5. de Candia F, Gargani L, Renzulli A (1990) J Appl Polym Sci 41:955-964

6. Hopfenberg H, Paul DR (1978) Transport phenomena in polymer blends, vol 1. Academic Press, New York

7. Stephen R, Varghese S, Joseph K, Oommen Z, Thomas S (2006) J Membr Sci 282:162-170

8. Stephen R, Joseph K, Oommen Z, Thomas S (2007) Compos Sci Technol 67:1187 
9. Wilson R, Plivelic TS, Aprem AS, Ranganathaiagh C, Kumar SA, Thomas S (2012) J Appl Polym Sci 123:3806-3818

10. Wilson R, George SM, Maria HJ, Plivelic TS, Kumar SA, Thomas S (2012) J Phys Chem C 116:20002-20014

11. Ahmad A, Mohd DH, Abdullah (2004) Iran Polym J 13:173-178

12. Kuriakose B, De SK (1986) Polym Eng Sci 26:34-44

13. John B (1984) In: Jensen C, (ed). AIC Book and Paper Group Annual, vol 3. The Oakland Museum of California, Oakland, pp 13-58

14. Maiti M, Bhowmick AK (2007) J Appl Polym Sci 105:435-445

15. Desai AB, Wilkes GL (1974) J Polym Sci 291-319

16. Billmeyer FW (1994) Text book of polymer science. Wiley Interscience, Singapore

17. Fujita H, Matsumoto K, Kishimoto A (1960) Trans Faraday Soc 56:424-443

18. Prager S, Bagley E, Long FA (1953) J Am Chem Soc 75:1255

19. Seehra MS, Yalamanchi M, Singh V (2012) Polym Testing 4:564-571

20. Jamnongkan T, Kaewpirom S (2010) Sci J UBU 1:43-50

21. Aminabhavi TM, Phayde HTS (1995) J Appl Polym Sci 55:1335-1352

22. Wang J, Wu W, Lin Z (2008) J Appl Polym Sci 109:3018-3023

23. Ganji1 F, Farahani SV, Farahani EV (2010) Iran Polym J 19: 375-398

24. Thomas PC, Tomlal Jose E, Selvin PT, Thomas S, Joseph K (2010) Polym Compos 31:1515-1524

25. Moly KA, Bhagawan SS, George SC, Thomas S (2007) J Mater Sci 42:4552-4561. doi:10.1007/s10853-006-0544-3

26. Van Amerongen GJ (1950) J Polym Sci 5:307-332
27. Kumnuantip C, Sombatsompop N (2003) Mater Lett 57: 3167-3174

28. Obasi HC, Ogbobe O, Igwe IO (2009) Int J Polym Sci Article ID 140682 doi: $10.1155 / 2009 / 140682$

29. Mathew L, Joseph KU, Joseph R (2006) Bull Mater Sci 29:91-99

30. Manoj KC, Kumari P, Rajesh C, Unnikrishnan G (2010) J Polym Res 17:1-9

31. Flory PJ, Jr Rehner J (1943) J Chem Phys 11:521-526

32. Ellis B, Welding GN (1963) Rubber Chem Technol 36:562

33. Jacques CHM, Hopfenberg HB (1974) Polym Eng Sci 14: $441-448$

34. El-Sabbagh SH, Yehia AA (2007) J Solids 30:2

35. Flory PJ (1953) Principles of polymer chemistry. Cornell University Press, Ithaca

36. Treloar LRG (1975) The physics of rubber elasticity. Clarendon Press, Oxford

37. Gent AN, Tobias RH (1982) J Polym Sci B Polym Phys 20:217-232

38. Cowie JMG (1991) Polymers: chemistry and physics of modern. Chapman and Hall, New York

39. Mahat BS (2010) Mathematical Models used in Drug Release Studies

40. Kim D, Caruthers JM, Peppas NA (1993) Macromolecules 26:1841-1847

41. Higuchi T (1963) J Pharm Sci 52:1145-1149

42. Korsmeyer RW, Gurny R, Doelker E, Buri P, Peppas NA (1983) Int J Pharm 15:25-35

43. Peppas NA, Sahlin JJ (1989) Int J Pharm 57:169-172 